\section{Seeing With New Eyes: My Professional Development Expedition as an Engineer}

\author{
Zaki Yamani Zakaria \\ School of Chemical and Energy Engineering, Faculty of Engineering, \\ Universiti Teknologi Malaysia, 81310 UTM Skudai, Johor \\ zakiyamani@utm.my
}

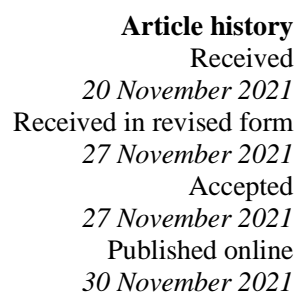

Abstract

Decision to be an engineer can be affected by hundreds of reasons. After a person successfully becomes an engineer, the next challenge is to pursue with engineering professional development, which is another context in the continuous learning process. This study's research question is "how and what are the trainings and processes for professional development to be a great engineer?" This study was conducted using the narrative inquiry and self-study method under the qualitative research paradigm. I use my blog entries as the primary qualitative data and narrative analysis as the main qualitative data analysis. Looking back more than three decades ago, I discovered the important turning point where I decided to be a chemical engineer. It was from that point of time; I gradually develop my engineering identity which is very crucial to the establishment of an indispensable engineer mind-set and character. Formal and informal education before, during and after university era combined as a meaningful chemical engineering roller coaster expedition. The excitement of learning new knowledge and gaining unique experience everyday resulted to the build-up of a matured chemical engineer. After a while, the process gracefully transformed from personally gaining to the integration of continuous learning and sharing, to benefit likeminded chemical engineering community. By showing this personal journey, I hope to enlighten the progression of professional development of an engineer.

Keywords: Chemical engineering identity, narrative inquiry, self-study, chemical engineer expedition.

\section{Introduction}

Being a developed country, Malaysia has tremendous potential to grow and prosper. In order to attain its full potential, the country has to pay a great deal of attention to the quality of engineering education, to ensure qualified engineering graduates, which are instrumental for the nation's growth and sustainable development. As stated by UNESCO, engineering has a significant role in dealing with the global issues from energy, climate change, water, safety and security, poverty, and sustainability problems (UNESCO, 2010). By resolving their own issues, developing countries, such as Malaysia, may play a role in tackling these global issues.

Fundamentally, engineer is an important building block of a nation. The more quality engineer a nation produces, the more developed and prosperous the country is. The profession as an engineer is very imperative to be gazetted to the young generation. In parallel with that, efforts to create interest in STEM among children must be strategically planned and executed by the government. In 2018, the National Council for Scientific and Research Development studied and revealed that Malaysia needs to have 500,000 scientists and engineers by 2020 to deal with the challenges of Industrial Revolution 4.0 (Vijaindren, 2018). Unfortunately, as of 2020, according to Board of Engineers, Malaysia (BEM), Malaysia only has 137,073 registered graduate engineers and professional engineers. For a developed nation, the engineer to population ratio should be $1: 100$. With a population of 32 million, Malaysia should have 300,000 registered and professional engineers (Fui, 2020). This is indeed a worrying scenario for Malaysia and other developing countries experiencing similar situation. What went wrong? What are the underlying issues brought to this unprecedented scenario? As for the case of young engineers, the realities of engineering practice is dynamic and constantly evolving, often leaving graduates underprepared for the workplace and employers dissatisfied with new engineers.

Every nation desire, plan and do their best to develop the country via a proper education system. The education system is diverse as it covers aspects of science technology and social sciences. Science and technology itself covers broad areas from engineering, technology, medical, architecture and others. After 64 years of independence, Malaysia has produced a lot of engineers. Thanks to the unremitting improvement of education system that among the focus are towards the establishment of engineers.

The next step after graduating is the route to be a professional engineer that is deemed very critical and continuous in the career development of an engineer. Continuous training emerged as a central role in helping engineers and their employers to respond positively to technical and commercial change (Senior, 1995). To encourage engineers to grow, plenty of 
activities such as workshops, trainings, conferences, lectures, seminars, refresher courses, colloquiums and work based activities were quantified as continuing professional development (CPD) (Schnehage, 2007). Due to numerous unhappy employers, recently Jesiek and his team investigated the early career progression for young engineers to comprehend their evolving job role demands and organizational expectations (Jesiek et al., 2021). He concluded that a synergistic improvement between engineering education and professional development should be performed.

The pertaining issues now are the process and training for young engineers in universities and after they graduate (in their career)? Is the training sufficient to make them a comprehensive and rigorous engineer? Is there a guided process to produce qualified, matured and indispensable engineer? The success of getting an engineering degree is one crucial element, but continuous development of the engineers themselves is another critical aspect. Are the engineers complacent with what they already achieved? Is the engineering degree certificate sufficient to allow them to practice? Did all engineering graduates served as practicing engineer or some of them lost their interest to be an engineer? How about the engineering identity development when they studied engineering? There are plenty of serious worrying questions.

Owing to the above tormenting issue, this study aims to conduct a narrative inquiry and self-study by reflecting on my professional development to be a professional engineer. So far there have not been such studies related to how a person undergoes professional development to be a professional engineer written using narrative inquiry and self-study method. Thus, this paper seeks to fill the existing gaps from the methodological aspects related to this theme. I shared the early stage of how I decided to be an engineer for us to reflect what could be the contributing factor of me choosing this path. After selfdetermining to be an engineer, I shared the processes I went through all the way until I became a professional engineer

\section{Methods}

The paper focuses on answering the research question "how and what are the trainings and processes for professional development to be a great engineer?" This paper was piloted using the narrative inquiry method under the qualitative research paradigm. This qualitative research method is based on the one introduced by (Connelly and Clandinin, 1990), which was then improvised further by (Clandinin and Caine, 2013). The narrative research design centralizes on the narrative of the life of an individual.

The fundamental principle of narrative inquiry is that humans are storytelling creatures who are individually or socially dwelling inside their own stories. Consecutively, the study of narrative, conferring to Connelly \& Clandinin (1990) is a research on how humans drive their lives in the world. In the context of educational research, this concept is developed into the perspective that education and educational researches are the construction and reconstruction of stories from one individual and a group of people socially. Learners, teachers, and researchers are storytellers and characters in their own stories or tell other people's stories.

In order to answer the research question, I have analysed my own professional development journey from being a high school student, then to an engineering student to becoming a practicing engineer and finally a professional engineer. I look through the lens of narrative inquiry and self-study to revisit my experiences in various selected professional developments as an engineer. Personal blog entries (Chemical Engineering World Blog) were employed as the primary qualitative data (Zakaria, 2007), and narrative analysis as the main qualitative data analysis. Personal blog entries were chosen because it is one method within a set of data collection methods and primarily for gathering information about experiences, perceptions, and feelings. Blogs have potential as a research tool for a range of purposes, including data collection (Wilson et al., 2015). Blog entries are also an intriguing form of communication and personal expression that resulted to the realization among researchers on the value that these media present as sources of data for research (Jones and Alony, 2007).

Narrative inquiry and self-study were chosen as the main qualitative data analysis because researchers commonly employ them to understand how research participants construct story and narrative from their own personal experience. Possible multiple theories and concepts that support the professional development in a person/career were identified for every episodes. These theories include Social Cognitive Career Theory, Self-Determination Theory, Transformative Learning Theory, Adult Learning Theory - Kolb's Learning Cycle, Circumscription and Compromise Theory, Community of Practice as a Social Theory of Learning. Simultaneously, concepts such as self-efficacy, transformative learning, and independent learning method were also considered in this study.

\section{Findings and Discussion}

\section{The beginning of the adventure}

Everything started when I was a venturesome adolescent and being in a background where my father was an organic chemistry professor. Being at that age, I was eager to learn and explore many things in a different way compared to when I was a child. I started to seek for my personal identity, interest and goal. I was fascinated when I first saw the chemical structures and formulas from my father's chemistry book. The chemical structures in the shape of pentagon, hexagon, heptagon and others look intriguing and fascinating to me. At that age, I felt that it could be a cool stuff to master and able to explain about the polygons. 
Since my father teaches organic chemistry in a local public university, he has dozens of related text books neatly arranged in our house and his office. In fact, he also co-authored an organic chemistry text book in our mother tongue language. When I was 14, I read one of his organic chemistry books and willingly motivated to learn chemistry by myself. When I was 17, I wanted to have a career associated with chemistry. I sturdily believe that this resemble a classic example of background contextual affordances such as families, particularly parents, whom have strong influences on the child's career choices (Ing, 2013). Even though my father did not persuade me into any career direction, his chemistry indulgent affected my interest and my future direction that is inclined to chemistry. Reflecting back in a deeper thought, I realized that my experience could be explained by the Social Cognitive Career Theory (SCCT)(Lent, 2004). According to SCCT, the choices people make and the actions of putting their choices into practice are related to their interests (Maiorca et al., 2021). The only thing to note, instead of majoring in chemistry, I decided chemical engineering pathway, mainly because I felt that it is more glamorous and prestige, based on what I knew at that time.

I recalled my uncle suggesting me petroleum engineering; however, I politely responded that I prefer chemical engineering. Although information on chemical engineering was scarcely available, I have the idea that this career is quite diverse and at the same time has specific crucial demand. Chemical engineers can fit and be in various industrial sectors and it is also regarded as a universal engineering discipline.

Back then at the end of my secondary school, my first choice was chemical engineering and my second choice was biochemistry. I was not really sure why I wanted to be a chemical engineer. But I know for sure it is not an influence of my parents such as majority of Saudi Arabian engineering students (Labib et al., 2021). I was also not pursuing chemical engineering because of it is a well-respected and well paid job as believed by most American chemical engineering students (Shallcross, 2002). The only thing I know is that I just love chemistry.

I did not know about the terminology of STEM (science, technology, engineering and mathematics) back then. But thinking about it, I realized that my interest in STEM could also be a motivating factor in me pursuing to be a chemical engineer. If I were to give straight direct answer of the reason, it would be due to my interest in chemistry. Even though I liked chemistry, I have no interest to be a chemist. The idea of becoming an engineer sounded better and by associating it with chemistry, I decided chemical engineer is a profession I would become. Many years after that, I realized that I was not the only one who picked chemical engineering due to my fond of chemistry. I can say majority of chemical engineers I met and chemical engineering students I teach (after I become a lecturer), chose chemical engineering because of their affection towards chemistry. In my opinion, this perception should be corrected. Chemical engineering is not solely about chemistry. It is more on mathematics and physics with certain extend of chemistry twist in between.

The journey during my tenure as a chemical engineering student was very challenging. There were several moments where I felt that it may not be possible for me to continue this course because of the difficulties in several subjects such as engineering mathematics, thermodynamics and reaction engineering. However, my engineering self-efficacy has driven me to the end, and I eventually graduated as a chemical engineer. Self-efficacy leads to an enduring interest in an activity. Self-efficacy is the self-perceived competence of an individual as stated by Bandura (Bandura, 1978). Every engineering student and young engineer should have strong self-efficacy to drive them to the end and also to keep them moving to get better and better.

To be honest, I was unaware of what chemical engineers do and what the industry is like. I could not imagine it due to lack of exposure and information. At that time, there was not internet to speed up information seeking. We relied on magazines or books that we can borrow from the library. We also count on information shared by those older and of more experience than us, but only God know the reliability and the accuracy of the information. I just knew that I want to be a chemical engineer and that my motivation is constructed around that idea. The motivation within me was very obvious and I started to develop my mindset and thinking as a person who will be a chemical engineer. This motivation is critical driving force as it helps to make me move and focus to one prime direction as stated by (Haque et al., 2014):

...Motivation is a way of creating high level of
enthusiasm to reach organizational goals, and
this situation is accommodated by satisfying
some individual need. Basically, motivation refers
to achieving organizational main goals by
satisfying individual employee's needs or
demands (p.2)

After completing my high school education, I pursued my A-Levels and took three core subjects which are essential for engineering: Physics, Chemistry and Mathematics. Then I continued my bachelor degree in chemical engineering. I managed to get a place in Bradford University, United Kingdom. I was unlucky because in our contract, practical training or sandwich course is not included by our sponsors. Therefore, we didn't have any valuable practical and industry exposures. That didn't matter and I kept on studying until I graduated in 1999. Reflecting on this particular episode, I can now reflect to the concept of Self-Determination Theory as introduced by (Ryan and Deci, 2020). No matter what the challenges were, I kept myself going and eventually graduated. 


\section{Post graduate - Research and Development (1999-2002)}

After completing my degree, I returned to Malaysia, immediately seek for an opportunity to work and was appointed as a research assistant for 5 months in UTM. I joined "Chemical Reaction Engineering Group" (CREG), where its main research at that time was developing a single step conversion of natural gas to gasoline using zeolite catalyst (Saidina Amin et al., 2001). It was a very interesting topic and that encouraged me to further my chemical engineering master's degree in it. Hence, I then became a full time research student and my research title was "Optimization of Oxidative Coupling of Methane (OCM) Using Experimental Design", which is part of the natural gas to gasoline research project (Saidina Amin and Zakaria, 2012).

I observed myself shifted from undergraduate learning style that focused on the conventional teacher-centred learning approach to a more matured and independent learning method (Jarvis, 2018). The process of learning was different but I am glad that I am comfortable with it. The learning initiative originated from me, my intrinsic motivation to learn and understand new knowledge. I began appreciating every moment at work and cherished the fact that I am learning from other more experienced and knowledgeable people within my circle. For example, I informally learned from my seniors, technicians, lecturers, supervisor, technicians, suppliers and others. This was a transition period which I can say related to an experience in new learning domain as depicted by Mezirow in his Transformative Learning Theory (Kitchenham, 2008). I enhanced my technical writing skills, communication and presentation skills and others while doing masters. In brief, a huge chunk of the learning and professional development was instigated by my own, which I utterly enjoyed very much.

\section{Oil \& Gas Exposure - Servicing Company (2003-2005)}

After completing my master, I was offered a job as chemical technologist for a local oil and gas servicing company. In a year, I became a project/chemical engineer in the same company. My main task was to lead the "internal pipeline chemical cleaning" (IPCC) project for a local oil company. We basically have to assist the oil company to reduce corrosion activities inside the downstream pipeline and prolong the life span of it. To efficiently and effectively monitor corrosion activities in the pipelines, we utilized latest corrosion monitoring techniques such as electronic resistant probe (ER) and field signature method (FSM).

I was also in charge of the oil and gas specialty chemicals. I travelled to a number of offshore platforms in East Malaysia to conduct deoiler and descaler tests (Figure 2 (a) and (b)) for their oil reservoir at PM9 Zone, South China Sea. It was very challenging and fun performing those tasks. I love going offshore because the working hours are less compared to the amount of time we spent on the offshore platform. The foods were marvellous and comparable to 5 star hotels. Entertainment and other activities such as television, movies, snooker, Ping-Pong, gymnasium and reflexology chair were made available for the platform dwellers. To be able to go offshore, I have to undergo Helicopter under Water Escape (HUET) training and get myself an offshore passport. With this job, I travelled extensively and visited neighbouring countries, Singapore and Indonesia, for work purpose. In Kalimantan, Indonesia, I joined our company principal to conduct bottle test field trial for local oil company on their onshore oil rig. It was a very interesting and exciting assignment because I got to see how simple the setting of an onshore oil rig because in Malaysia we only have expensive and complicated offshore oil rigs/platforms.

The whole practical exercise that I went through can be related to the Adult Learning Theory (Merriam, 2008), particularly Kolb's Learning Cycle (Figure 1), which I found to perfectly fit what I experienced. Kolb's Learning Cycle is based on the Jean Piaget's focus on the fact that learners create knowledge through interactions with the environment and his work (Kolb, 2015).

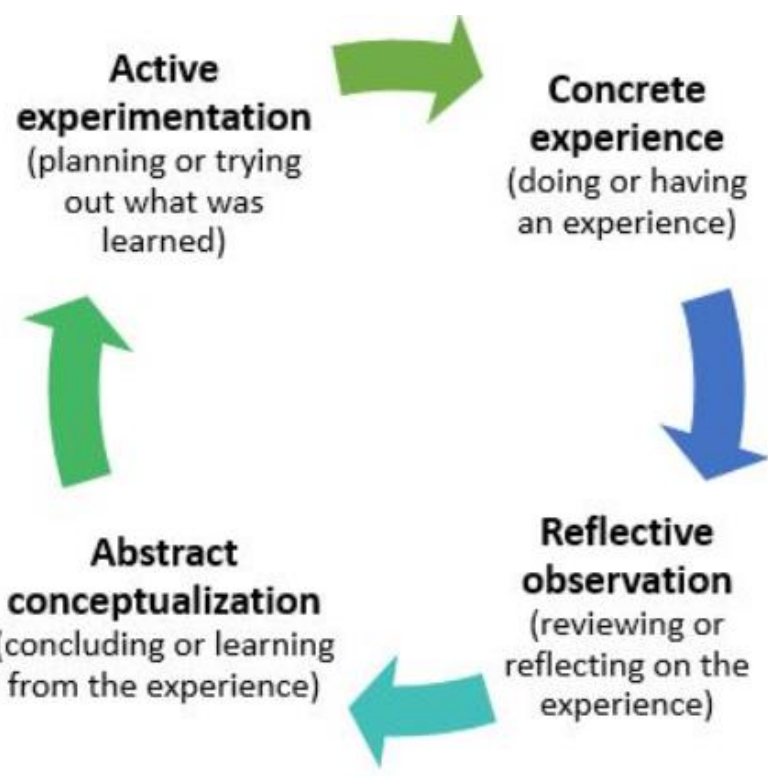

Figure 1: Kolb's learning cycle

Kolb's learning cycle concept is enhanced by Kolb's Four Stages of Learning that are (i) Concrete Experience, (ii) Reflective Observation, (iii) Abstract Conceptualization; and (iv) Active Experimentation.

To better illustrate the relationship, I selected a specific practical process during my work in the oil and gas industry. The first stage stated that the learning process begin with "Concrete Experience". In 2003, I started my first endeavour working in a site of a petroleum processing company. Our task was to protect the pipeline by internal pipeline chemical cleaning. I never imagine or expected to do such work. Honestly, I did not know or have ever imagined that there is a job like that. The trip to a gas processing 
facility located at the east cost of Peninsular Malaysia in early January 2003 was my first time and it was a very enriching one that I learned a lot in terms of the technicality, management and operation. Not only that, I immediately found myself to lead a group of contract workers, whom are all older and more experienced than me. I have to properly communicate and lead them to accomplish my task. Kolb stated that the first stage can either be a completely new experience or a reimagined experience of what had happened. In this stage, I was highly engage in the 5 days project and the key to learning at this point is by being involved. It is not sufficient if I only learn about it by listening to my superior or manager's briefing. Bottom line is to be actively engaged in the task.

The second part of Kolb's Four Stages is Reflecting Observation and into certain extend, even not thorough, I did glanced to reflect on the overall experience during the IPCC project. Every day after the sub-task was completed; I recalled the experiences and often ask questions and discussed it with my colleagues and superiors on the task, how it went, what should be done better and how to improve it. This occasionally occurred at our hotel and over dinner. From this exercise, I managed to identify any discrepancies between their understanding and the experience itself. The reflection observation learning process is optimum within the 12 hours period after the daily sub-project ended as I can still clearly recall on the detailed performed tasks. For example, I did asked about the methods of how to launch a pig in the
10" and 48" (Figure 2(c)) pipeline that requires strategic coordination of valves operation between our team and the client's team to create safe pressure difference to enable the pig to initialize travelling (Figure 2(d)). Pig in this context (pigging activity) is an equipment that is inserted in pipeline for various purposes such as for cleaning or for carefully spreading chemical film in the internal side of the pipeline or others.

Next will be the Abstract Conceptualization where I make sense of the events. I attempted to draw conclusion of my experience by reflecting on my prior knowledge, using ideas which I am familiar or discussing possible theories/ concepts/ hypothesis/ methods with my colleagues. I began to move from reflective observation to abstract conceptualization when I began to classify concepts and form conclusions on the events that occurred. This involves interpreting my experience and making comparisons to my current understanding on the concept. The tasks/ activities became clearer as I assisted to document them into various reports such as Method of Statement (MOS), Emergency Response Procedure (ERP), Job Completion Report (JCR) and Quarterly Progress Report and others. The reports require observation/ findings, data capturing/ analysis, suggestions/ recommendations and others. At first, I am not familiar with the reporting and documentation exercise, but with time I get better and was able to handle it myself. From this exercise, the overall tasks or bird eye view of the entire project makes sense.

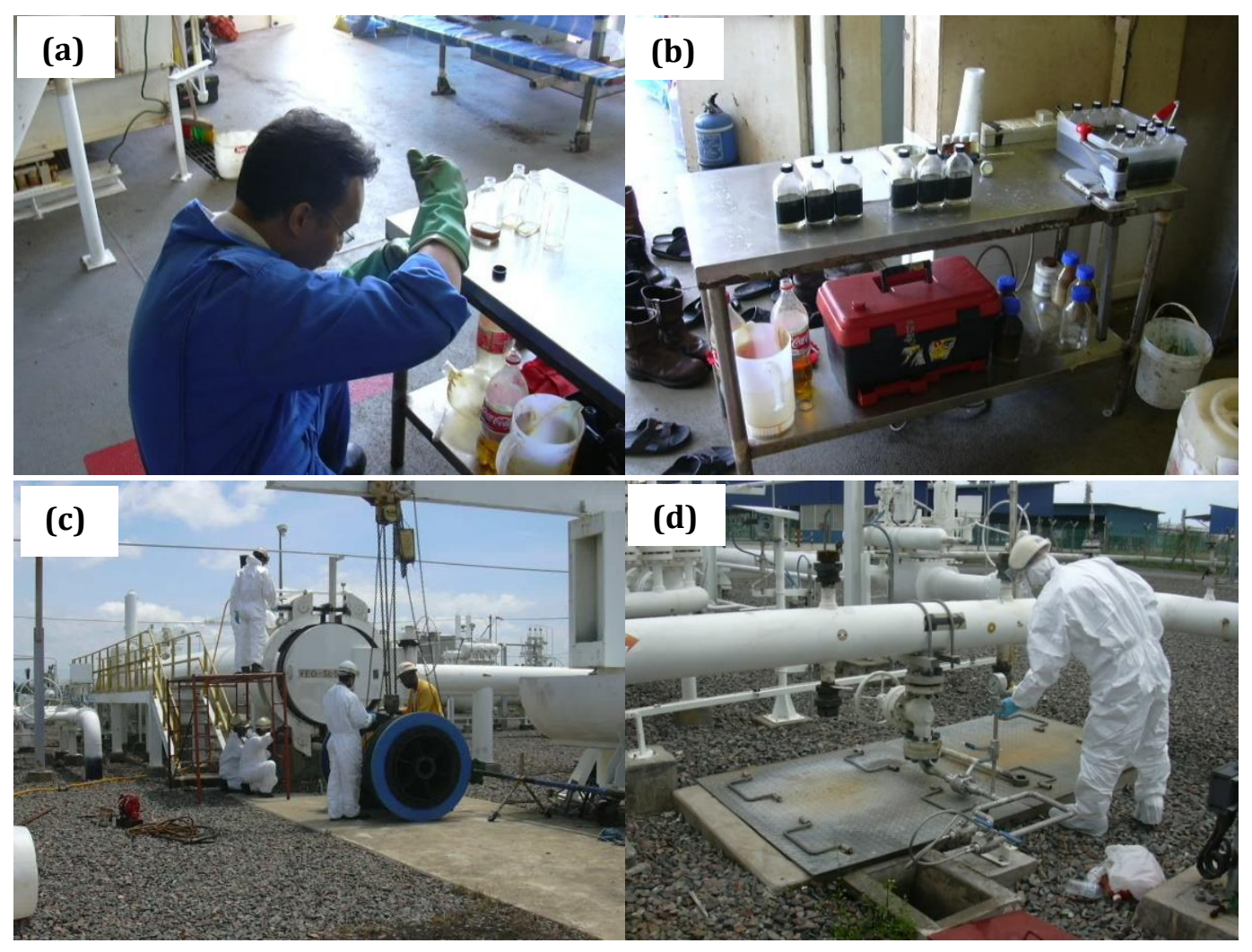

Figure 2: (a) Performing bottle test at one of the offshore platforms I was assigned to (b) My work kit to perform the bottle test (c) A 48" pig was about to be set up in a 48" gas condensate pipe launcher (d) Checking pressure reading on the gas pressure regulator at the receiver side of a 10" pipeline 
The final stage is the Active Experimentation where it is also referred to as testing stage. In this context, I return to participate in the same project after three months, this time with the goal of applying my previous conclusions to new experiences. Thereafter, every quarterly I managed to improve and get sharper. I am able to make predictions, analyse tasks, and make plans for the acquired knowledge in future activities. I allow myself to put my knowledge into practice and showed how it is relevant to me, and how I can ensure that the information is retained in the future. This can be seen when I managed to take part in the planning, mobilization-demobilization, project execution, management and reporting of the project. I also managed to develop good relationship with the client and at the same time maintain my professionalism as an engineer and also the representative of the company I worked with.

As Kolb's learning theory is cyclical, one can enter the process at any stage in the cycle. Even though I never formally knew about the theory, as I associate my past working experience with the Kolb's learning theory, I realized that I am actually learning as per say in the context of On-Job-Training. The cycle should be completed in entirety to ensure that effective learning has taken place. Each stage is dependent on the others and all must be completed to develop new knowledge.

\section{Oil \& Fats Industry - Refinery (2005-2008)}

I love my oil and gas career but I was unfortunate because I could not continue being in that industry. The company management has bigger plans and they moved to Kuala Lumpur, the capital of Malaysia, in quest to seek for more business opportunities. I was instructed to transfer which I could not do because I don't want to hinder my wife's career establishment as a lecturer/researcher/consultant in UTM and we also have just purchased a house in Johor Bahru, the same year. That was the situation at that time. Personally, I learned to compromise and negotiate with the situation. Everything will not go our way or how we plan and wanted it to be. Hence, we need to have acceptance, adapt and move forward. I swiftly seek for a new engineering job that can allow me to keep on contributing my expertise and at the same time for my family's survival.

My state of mine at this time can be associated with the Circumscription and Compromise Theory. This theory, developed by Linda Gottfredson in 1981, attempts to describe how career choice develops in young people. Many developmental theories focus on how an individual's self-concept develops with age. Circumscription and compromise also focuses on the development of an individual's view of the occupational choices available. The theory assumes that we build a cognitive map of occupations by picking up occupational stereotypes from those around us. Occupations are placed on this map using only a small number of dimensions: sex-type, prestige level and field of work. As young people build this map, they begin to decide which occupations are acceptable and which are unacceptable - those which fit with their own developing self-concept and those which do not.

I seek for other jobs and managed to get one in a physical refining plant in the oil and fats industry located in Johor Bahru, but $50 \mathrm{~km}$ away from my house. This is a whole new chapter and totally different from my previous job. I was required to punch in and out every time we enter or exit the refinery/factory. Life is no longer as flexible as before. I don't have ample time to do my work and that made me work longer hours and I always reach home when it's already dark. I don't really mind because it's a new working environment and I know I have to learn as fast as possible, just the same principle as the Kolb's Learning Cycle. I set my target to know everybody around my circle of work as soon as possible. Reflecting this intention, I can relate it to the Community of Practice as a Social Theory of Learning (Farnsworth et al., 2016).

The workplace community I was in consisted of plant supervisor, plant operators, maintenance supervisors, colleagues such as process engineers and production executives from other departments. All of them have great experiences and certain specific technical knowledge and the whereabouts of the workplace. It turns out that by casually socializing with them, I can swiftly and effectively learn. I can discuss and consult with them as well. However, I was reminded by manager not to be too close or too intimate with my down-line staffs. At first I was confused with this advice and felt that it does not make sense. This is because, my reasoning back then was, and it is good to be close to our staffs so we can work productively and comfortably. It took me 6 months after that to realize the logic behind the advice where I need to evaluate the performance of all my staffs. The evaluation will affect the annual salary increment and yearly bonus. At that time, I was already quite close with some of my staff and I felt that it is difficult to evaluate them fairly and professionally if we are emotionally and socially attached to them. I may tend to grade those close to me with slightly higher marks, only for me to be reminded by my manager that I was biased when I submitted my evaluation.

Here I realized that I have indulged in a conflict of interest issue and I was not professional and ethical in giving my marks. I then recalled the advice given to me by my manager earlier to draw a thin line border to control my relationship with my staffs. As a person who has not formally be educated in ethics or ethics case studies/examples during the undergraduate years, I learned the hard way. I learned this through the context of Adult Learning Theory. I also realized that, there are more than just being qualified and getting certificate as an engineer. In university, me and my friends have not been taught or properly trained to be a good leader, team player, possess immaculate soft skills such as communication, presentation, writing skills. We have not been taught on emotional intelligence and empathy. I have to learn all of the above mentioned soft skills by myself. I learned 
through my own experience and luckily I really wanted to improve, and could relate this to the Self Determination Theory (Deci and Ryan, 2012). I was determine to improve myself to be good and an indispensable engineer. This is when I see that I improved cognitively and technically with time.

On the first week of my tenure as a process engineer, my first task given by my Manager was to identify and list down all the valves in the plant I was in charge of. It was an interesting and good assignment. It made me traced the entire pipeline from the feed tank to the plant and to the product tank. I learned a lot of technical knowledge regarding valves. I know and understand various types of valves, brands, origin, sizes, spare parts, principles, operations, tag numbers etc. In addition to that, indirectly, I learned about the plant process and operation. That was just the beginning. Being in a process plant is a perfect place to learn and put in practice my unit operation knowledge. It also gave me a better comprehension on what process control is all about. I learned about other supporting units like heat exchangers, cooling towers, high pressure boilers, utility boilers and much more. During plant shut down, I learned a lot. Techniques on ensuring the fastest and effective way to cool down the plant, managing and coordinating a team of people to service the plant, conducting air test, steam test and driving the plant start-up are among some knowledge I acquired.

The learning curve continued every day and never stopped. Not only that I learn about all the technical aspects, handling manpower and managing conflict is another challenging area that I made myself good at. Manpower is not an easy matter to deal with. Some of my down line manpower never experienced any disciplinary action taken when they violated certain laws such as coming in late and simply not coming to work. Despite a series of reminder and warning, the bad attitude still continues. I could not stand it. Together with my senior colleague, we enforced the discipline and forced them to obey. We gave the problematic staffs some disciplinary action. We wanted them to learn a lesson and be more serious towards their responsibility and work. They got the message and swiftly improved positively at work.

\section{The Turning Point to be Professional Engineer (2007)}

I have to say that even though I am a practicing chemical engineer, I also have the desire to be an academician. For the past five years after I became an engineer, I have attempted five times to get to an interview to be an academician. I almost gave up, thinking that I will end up becoming an engineer for the rest of my life. Deep inside, I know that I can contribute far more as an academician compared to as a practicing engineer. Even as an academician, I still regard myself as a chemical engineer but then in the educational sector. My self-determination and motivation was still high. Reflecting back the past five years, I knew I must improve myself and introduce a WOW factor so that I can be accepted as an academician. Besides depending on my engineering practice experiences, I decided that I must start leading my way to be a professional engineer.

I was still a practicing engineer when I consulted few friends that I know who are a professional engineer and also the Board of Engineers, Malaysia (BEM) and Institution of Engineers, Malaysia (IEM). I managed to get in touched with a very experienced Professional Engineer who became my mentor. Although he is $350 \mathrm{~km}$ apart from me, I regularly communicated with him and also visited him every quarter of the year to report on my progress.

My mentor was a very strict and wise person. He advised and guided me brilliantly. At one point, I was reminded by him that I could not have repeated engineering activities month after month. I must diversify and show more engineering activities. To achieve that, I need to request for other engineering tasks and projects to enable me to have a more colourful activities reported in my Logbook, Final Project Report and Training \& Experience Report. In 2008 , I was successfully accepted as an academician in a local university, the same university I have attempted to apply for five straight years. My mentor said that my move to be an academician was a perfect one as I can decorate more variety of engineering activities in my Logbook. Finally in October 2010, I passed my Professional Interview as a professional engineer and began a new chapter. The process was definitely not easy, but again my intrinsic determination, as depicted by the Self Determination Theory once again facilitated me to emerge victorious.

\section{Serving as a Professional Engineer (2010 onwards)}

The year 2010 was an amazing year for me. I was working on my $\mathrm{PhD}$ and I earned my Professional Engineer status, granted by BEM. Three months after that I sat for an interview to be a Chartered Engineer under the Institution of Chemical Engineer (IChemE), UK. Two months after that, my application to me a Chartered Engineer was successful. Ever since that, I do my part to create awareness, wrote a blog post to share information on how to be a Professional engineer (Zakaria, 2014). I also help graduates who wanted to apply by signing, stamping and endorsing their application besides also providing advice or consultation to young engineers and engineering students. I ensured that I will support or attend any activities conducted by our IEM or IChemE student chapters in the university.

On top of that I keep on developing myself by participating in various technical visits arranged by IEM Southern Branch. Among the technical visits was the Legoland construction project at Nusajaya, Johor; NEWater Facility Plant in Singapore (Figure 3(a)); MRT Construction project in Singapore; Claytan Group at Air Hitam (Figure 3(b)), Mechmar Boiler at Pasir Gudang, Johor (Figure 3(c)); Malakof Power Plant at Tanjung Bin, Johor; and INSTEP Virtual Technical visit (Figure 
$3(d))$, to name a few. All of the technical visit were unique and provided me numerous experiences that I can relate to the Kolb's experiential learning theory (Healey and Jenkins, 2000). Although all of the technical visits are unique and a one-off type of experience, it is still worthy and precious as I learned to relate, understand and appreciate other engineering discipline domains. The technical visit rejuvenates me as it breaks my ordinary life-job routine. The technical visits also allow me to socialize with other practicing professional engineers, thus widening my networking horizon. This learning and professional development differs a bit from the Kolb Learning cycle previously discussed during my oil and gas endeavour tenure (because this was my job scope that I repeatedly performed and improved along the way).

In mid-2021, I decided to be active in IEM and found myself dynamically involved in the Safety Engineering Special Interest Group (SESIG), under IEM. I was elected as SESIG committee member and I am presently doing my best to contribute to the nation through IEM. Simultaneously, I am also leading a team under a project called Safety Champions in Engineering Education, a fellowship program organized by the Royal Academy of Engineering (RAE), United Kingdom that commenced in the third quarter of 2021. Having experienced as a practicing engineer and now actively involved in teaching as well as venturing into engineering education, I am doing my best, my part, to contribute the best to the country, region and world. I sincerely hope and pray that our next generation of engineers will be of high quality and resilient. I wish that my professional development expedition as an engineer will provide insightful ideas, new dimensions and context for young engineers to mature as an indispensable engineer.

\section{Conclusion}

Reflecting on my professional development expedition to be a professional engineer, it can be concluded that there are plenty occasions and factors that serves as a training process in developing and shaping me to the state I am now. Upon seeing the past experiences with new eyes, I realized that multiple theories can be deeply associated with specific scenario. The integration of the contributing theories will be my focus on future narrative analysis and selfstudy. The narrative of my journey above also teaches us that the journey of a person's professional development is unique and personal.
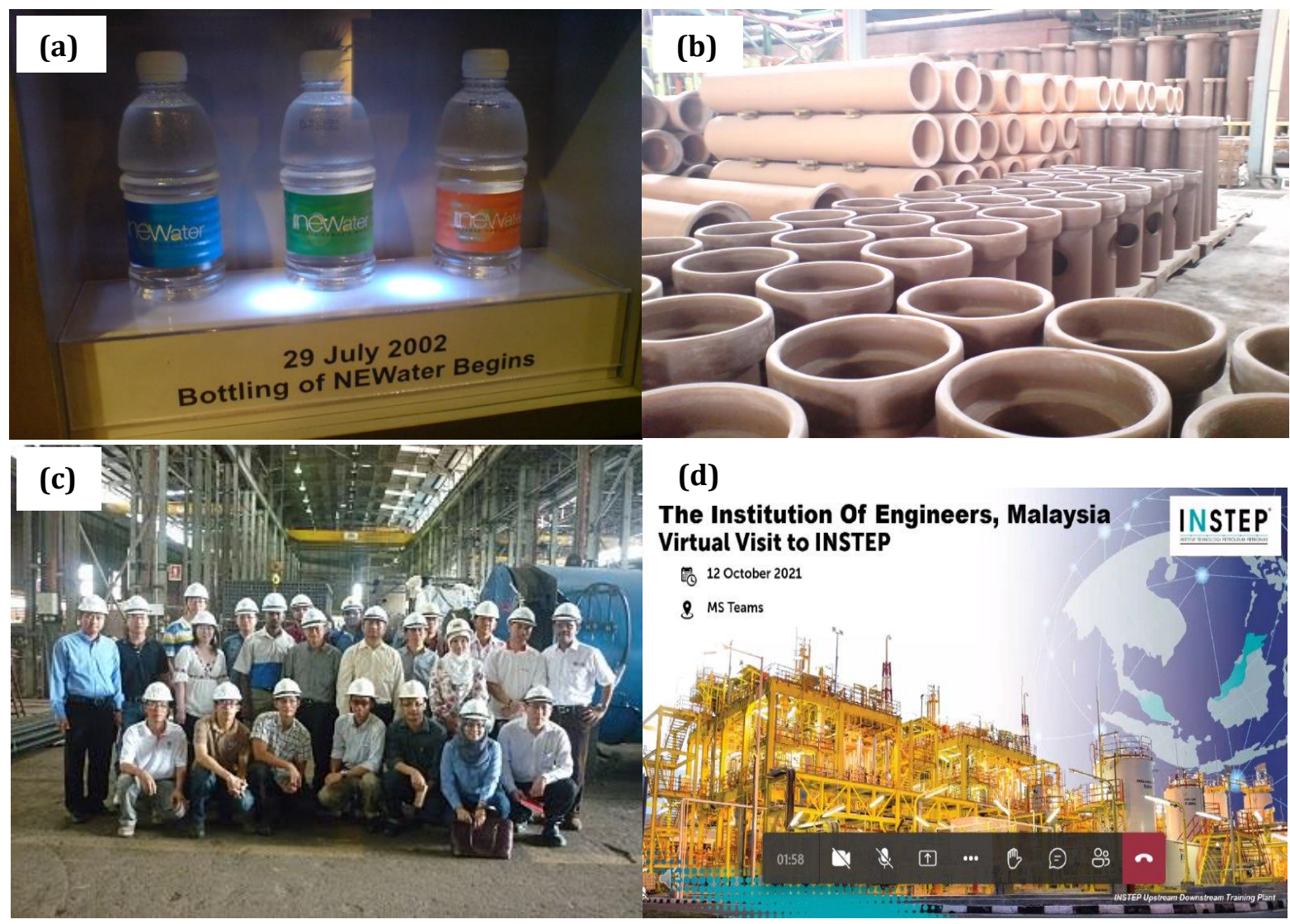

Figure 3: (a) Technical visit to Newater Facility, Singapore in 2008; (b) Clay pipes products from the technical visit to Claytan Group in Air Hitam, Johor in 2008 (c) Technical visit to Mechmar Boiler company in Pasir Gudang, Johor in 2012 (d) INSTEP Virtual visit, Terengganu in 2021. 
The findings of this study have convey that an engineer's professional development involved various reasons, factors, motivation and could be connected to relevant social theories. Most importantly, a synergistic exertion between engineering education (before, during and after higher education) and professional development (before and during engineering employment) should be performed. This process could motivate and aid engineers to be more resilient and indispensible, making them useful for their employer, community and nation. I sincerely hope that my professional development as an engineer narratives can provide at least some useful information for fellow young engineers. I also believe it is good if other professional and practicing engineers out there can do the same for others to benefit. It will be a great contribution.

\section{Acknowledgement}

I would like to express my gratitude to Universiti Teknologi Malaysia (UTM) (http://www.utm.my) and the Ministry of Higher Education Malaysia (MOHE) for supporting this project under the UTM Matching Grant (Ref. No: PY/2016/06327; Cost Center No. Q.J130000.3023.00M94).

\section{References}

Bandura, A. 1978. Self-efficacy: Toward a unifying theory of behavioral change. Advances in Behaviour Research and Therapy, 1, 139-161.

Clandinin, D. J. \& Caine, V. 2013. Narrative inquiry. Reviewing qualitative research in the social sciences. Routledge.

Connelly, F. M. \& Clandinin, D. J. 1990. Stories of Experience and Narrative Inquiry. Educational Researcher, 19, 2-14.

Deci, E. L. \& Ryan, R. M. 2012. Self-determination theory. Handbook of theories of social psychology, Vol. 1. Thousand Oaks, CA: Sage Publications Ltd.

Farnsworth, V., Kleanthous, I. \& Wenger-Trayner, E. 2016. Communities of Practice as a Social Theory of Learning: a Conversation with Etienne Wenger. British Journal of Educational Studies, 64, 139-160.

Fui, W. C. 2020. Time we recognise and retain our engineers. New Straight Times, February 19, 2020

Haque, M., Haque, M. \& Islam, M. S. 2014. Motivational Theories - A Critical Analysis. 8.

Healey, M. \& Jenkins, A. 2000. Kolb's Experiential Learning Theory and Its Application in Geography in Higher Education. Journal of Geography, 99, 185-195.

Ing, M. 2013. Can Parents Influence Children's Mathematics Achievement and Persistence in STEM Careers? Journal of Career Development, 41, 87-103.

Jarvis, P. 2018. Learning to be a person in society. In: ILLERIS, K. (ed.) Contemporary Theories of Learning. 2nd Edition ed. London: Taylor \& Francis.
Jesiek, B., Buswell, N. \& Nittala, S. 2021. Performing at the Boundaries: Narratives of Early Career Engineering Practice. Engineering Studies, 13, 1-25.

Jones, M. \& Alony, I. 2007. Blogs - The New Source of Data Analysis. Faculty of Commerce - Papers, 5.

Kitchenham, A. 2008. The Evolution of John Mezirow's Transformative Learning Theory. Journal of Transformative Education, 6, 104-123.

Kolb, D. A. 2015. Experiential Learning: Experience as the Source of Learning and Development, New Jersey, Pretince Hall.

Labib, W., Abdelsattar, A., Ibrahim, Y. \& Abdelhadi, A. 2021. What Motivates Students to Study Engineering? A Comparative Study between Males and Females in Saudi Arabia. Education Sciences, 11.

Lent, R. 2004. Toward a Unifying Theoretical and Practical Perspective on Well-Being and Psychosocial Adjustment. Journal of Counseling Psychology, 51, 482-509.

Maiorca, C., Roberts, T., Jackson, C., Bush, S., Delaney, A., MohrSchroeder, M. J. \& Soledad, S. Y. 2021. Informal Learning Environments and Impact on Interest in STEM Careers. International Journal of Science and Mathematics Education, 19, 45-64.

Merriam, S. B. 2008. Adult learning theory for the twenty-first century. New Directions for Adult and Continuing Education, 2008, 93-98.

Ryan, R. M. \& Deci, E. L. 2020. Intrinsic and extrinsic motivation from a self-determination theory perspective: Definitions, theory, practices, and future directions. Contemporary Educational Psychology, 61, 101860.

Saidina Amin, N. A., Anggoro, D., Zakaria, Z. Y., Prasetyoko, D., Tan, E. F., Law, K. M. \& Esam, A. 2001. Catalytic activity of Cu-ZSM-5 and HZSM-5 zeolite for single step conversion of methane to liquid hydrocarbon.

Saidina Amin, N. A. \& Zakaria, Z. Y. 2012. Optimization of Oxidative Coupling of Methane Using Response Surface Methodology. Jurnal Teknologi, 39, 35â€“52.

Schnehage, C. 2007. Continuing Professional Development (CPD) and the engineer. 10-11.

Senior, C. 1995. Strategies for Professional Development in Engineering. Industry and Higher Education, 9, 236-240.

ShallcrosS, D. 2002. Perceptions Of The Chemical Engineering Profession - Results Of An International Survey.

Unesco 2010. Engineering: Issues, Challenges and Opportunities for Development. Paris, France.

Vijaindren, A. 2018. Malaysia needs 500,000 scientists and engineers by 2020. New Straight Times, August 13, 2018

Wilson, E., Kenny, A. \& Dickson-Swift, V. 2015. Using Blogs as a Qualitative Health Research Tool: A Scoping Review. International Journal of Qualitative Methods, 14, 1609406915618049.

Zakaria, Z. Y. 2007. Chemical Engineering World Blog. Chemical Engineering World Blog [Online]. Available from: http://chem-eng.blogspot.com 2021]

Zakaria, Z. Y. 2014. How to be a Professional Engineer (PE) with IR Status? Chemical Engineering World [Online]. Available from: http://chem-eng.blogspot.com/2014/07/how-tobe-professional-engineer-pe-with.html [Accessed July 8, $20142014]$. 